\title{
Cyber-victimization and its association with depression among Vietnamese adolescents
}

\author{
Truc Thanh Thai ${ }^{\text {Corresp., }}{ }^{,}$, Mai Huynh Thi Duong ${ }^{2}$, Duy Kim Vo ${ }^{3}$, Ngan Thien Thi Dang ${ }^{4}$, Quynh Ngoc Ho Huynh ${ }^{1}$, \\ Huong Giang Nguyen Tran ${ }^{\text {Corresp. } 5}$ \\ 1 Faculty of Public Health, University of Medicine and Pharmacy at Ho Chi Minh City, Ho Chi Minh City, Vietnam \\ 2 Pasteur Institute in Ho Chi Minh City, Ho Chi Minh City, Vietnam \\ 3 Long Dien District Medical Center, Ba Ria Vung Tau, Vietnam \\ 4 Pham Ngoc Thach hospital at Ho Chi Minh City, Ho Chi Minh City, Vietnam \\ 5 Training and Scientific Research Department, University Medical Center Ho Chi Minh City, Ho Chi Minh City, Vietnam \\ Corresponding Authors: Truc Thanh Thai, Huong Giang Nguyen Tran \\ Email address: thaithanhtruc@ump.edu.vn, huong.tng@umc.edu.vn
}

Background: Cyberbullying has become an alarming social issue, but little is known about its prevalence and consequences in many countries. This study investigated the prevalence of cyber-victimization and its association with depression among students in Ho Chi Minh City, Vietnam. Methods: A cross-sectional study was conducted in 1492 students from eight secondary schools and high schools in four urban and suburban areas. Multi-stage cluster sampling approach was used to recruit participants. Students participated in this study on a voluntary basis and completed a self-report questionnaire that included validated scales to measure their experience of cyber-bullying (Cyber Bullying Scale) and symptoms of depression (Center for Epidemiologic Studies Depression Scale). Weighted logistic regression analysis was used to adjust for the cluster effect and sampling probability. Results: Almost all (92.4\%) students reported using the internet everyday and nearly $40 \%$ used internet for more than four hours per day. Cybervictimization was identified in $36.5 \%$ of students and almost $25 \%$ experienced multiple types of cyber-victimization. Nearly half of students reported symptoms of depression. After adjusting for other covariates, students who experienced cyber-victimization were found to have 1.81 times $(95 \% \mathrm{Cl} 1.42-2.30)$ higher in odds of having symptoms of depression. Conclusions: Cyber victimization and depression are both common in Vietnamese adolescents. Those who experienced cyber bullying have a higher likelihood of having symptoms of depression. These findings indicate an urgent need for interventions and policies targeting this emerging type of bullying in Vietnam and similar settings due to its potential harmful effects on adolescents' health. 


\section{Cyber-victimization and its association with depression among}

\section{Vietnamese adolescents}

3 Truc Thanh Thai ${ }^{1}$, Mai Huynh Thi Duong ${ }^{2}$, Duy Kim Vo ${ }^{3}$, Ngan Thien Thi Dang ${ }^{4}$, Quynh Ngoc

4 Ho Huynh ${ }^{1}$, Huong Giang Nguyen Tran ${ }^{5}$

5

$6 \quad{ }^{1}$ Faculty of Public Health, University of Medicine and Pharmacy at Ho Chi Minh City, Vietnam.

7 2Pasteur Institute in Ho Chi Minh City, Vietnam.

$8 \quad{ }^{3}$ Long Dien District Medical Center, Ba Ria - Vung Tau, Vietnam.

$9 \quad{ }^{4}$ Pham Ngoc Thach Hospital at Ho Chi Minh City, Vietnam.

$10{ }^{5}$ Training and Scientific Research Department, University Medical Center Ho Chi Minh City, 11 Vietnam.

Corresponding author:

Truc Thanh Thai, Faculty of Public Health, University of Medicine and Pharmacy at Ho Chi

Minh City, Vietnam. Phone: +84 908381 266. Email: thaithanhtruc@ump.edu.vn. ORCID ID: 0000-0003-2512-8281 Huong Giang Nguyen Tran, Training and Scientific Research Department, University Medical Center, Ho Chi Minh City, Vietnam. Phone: +84 916154 524. Email: huong.tng@umc.edu.vn.

\section{Abstract}

Background: Cyberbullying has become an alarming social issue, but little is known about its prevalence and consequences in many countries. This study investigated the prevalence of cybervictimization and its association with depression among students in Ho Chi Minh City, Vietnam. Methods: A cross-sectional study was conducted in 1492 students from eight secondary schools and high schools in four urban and suburban areas. Multi-stage cluster sampling approach was used to recruit participants. Students participated in this study on a voluntary basis and completed a self-report questionnaire that included validated scales to measure their experience of cyber-bullying (Cyber Bullying Scale) and symptoms of depression (Center for Epidemiologic Studies - Depression Scale). Weighted logistic regression analysis was used to adjust for the cluster effect and sampling probability. 
31 Results: Almost all (92.4\%) students reported using the internet everyday and nearly $40 \%$ used

32 internet for more than four hours per day. Cyber-victimization was identified in $36.5 \%$ of students and almost $25 \%$ experienced multiple types of cyber-victimization. Nearly half of students reported symptoms of depression. After adjusting for other covariates, students who experienced cyber-victimization were found to have 1.81 times $(95 \%$ CI $1.42-2.30)$ higher in odds of having symptoms of depression.

Conclusions: Cyber victimization and depression are both common in Vietnamese adolescents. Those who experienced cyber bullying have a higher likelihood of having symptoms of depression. These findings indicate an urgent need for interventions and policies targeting this emerging type of bullying in Vietnam and similar settings due to its potential harmful effects on adolescents' health.

Keywords: Cyber-victimization; Cyberbullying; Depression; Adolescent; Vietnam

\section{Introduction}

Cyberbullying refers to any kinds of harassment through emails, chat rooms, websites or messages that inflict emotional distress on others ${ }^{1}$. In most countries, including Vietnam, there is an increasing trend in the number of internet users with the dominance of adolescents ${ }^{2}$. In 2020 , Vietnam is among the top 20 countries in the number of internet users and is estimated to reach more than 71 million users in $2021^{3,4}$. There is evidence that adolescents are at a high risk of becoming victim of cyberbullying ${ }^{5,6}$. A meta-analysis of 131 studies evaluating the prevalence of cyberbullying from 2002 to 2013 revealed that $10 \%-40 \%$ of adolescents were cyber-victimized ${ }^{5}$. A comparative analysis of existing reports in ASEAN countries found that the rate of cyber-victimization in adolescents has increased significantly in recent years ${ }^{6}$. For example, in Philippines, this rate was especially high, up to $80 \%$ in 2015 , although the government had enacted the Anti-Bullying Law against cyberbullying in $2013^{7}$. In Vietnam, a study conducted among secondary and high school students in northern provinces showed that approximately $81 \%$ of students had suffered from cyberbullying ${ }^{8}$.

Recently, cyberbullying has developed further into different types such as cancel culture, cyberstalking, flaming, trolling, masquerading and many others. Cyberbullying has become an alarming social issue not only because of its rising rate but also its serious physical and psychological consequences on adolescents 5,9 . A systematic review revealed a relationship between cyber-victimization and moderate to severe symptoms of depression among 12-17- 
62 year-old students ${ }^{9}$. For example, a study in Sweden among 1214 students aged 13 to 16 found 63 that students who experienced cyber victimization had up to 3.41 times higher in odds of having

64 depression ${ }^{10}$. Another study in the USA of 20,406 students in grade 6-12 reported that the rate of depressive symptoms was 2.61 times higher among cyber-bullying victims ${ }^{11}$. However, in Vietnam, research on this issue is still lacking and no study has been conducted in Ho Chi Minh City. Due to the lack of scientific evidence, interventions and policies against cyber bullying are also limited.

To date, there have been several studies conducted in Vietnam to evaluate depression and its potential risk factors. In 2011, a study of 1161 students in Can Tho City showed that $41.1 \%$ students had depressive symptoms. Students who did not live with their parents, being physically or mentally abused, have poor academic performance and high study pressure were more likely to develop depressive symptoms ${ }^{12}$. Another study of 6407 students found that $31.7 \%$ of students experienced depression. Noticeably, traditional bullying was found to be a significant risk factor of depression among students ${ }^{13}$. Ho Chi Minh City is one of the most important economic, political, cultural, and educational centers in Vietnam ${ }^{14}$. There is a syndesis in the prevalence of both internet use and depression in adolescents in this city with nearly $60 \%$ of students having symptoms of depression ${ }^{15}$. Apart from the known risk factors of depression, it is possible that there is an association between cyber-victimization and depression. If this hypothesis is true in Vietnam, as in other countries, more attention should be paid to internet-using habits and cybervictimization because of their negative impacts on adolescents' health.

Therefore, the objective of this study was to investigate the prevalence of cybervictimization and its association with depression among students in Ho Chi Minh City. The study serves as scientific background for further interventions for Vietnamese adolescents.

\section{Materials \& Methods}

\section{Settings and participants}

A cross-sectional study was conducted in May 2020 in Ho Chi Minh City, Vietnam. At the time we conducted the study, there was no lockdown enforcement due to Covid-19 and all schools were open. The city had 272 public secondary schools and 110 public high schools across 24 districts (19 urban and 5 sub-urban). Multi-stage cluster sampling technique was use to recruit participants. We randomly selected four districts ( 3 urban and 1 sub-urban), resulting in the selection of District 3, 5, Tan Phu and Hoc Mon. At each district, one secondary school and 
93

94

95

96

97

98

99

100

101

102

103

104

105

106

107

108

109

110

111

112

113

114

115

116

117

118

119

120

121

122

123

one high school were randomly selected from a existing list of schools provided by the Department of Education and Training. At each school, two classes in each grade were randomly selected from the list of classes. For secondary schools, only grade 8 and 9 were selected due to the anticipated potential information bias where young students might not fully understand the questions in the questionnaire. For high schools, all three grades (i.e., grade 10, 11, 12) were selected. A total of 40 classes from 4 secondary schools and 4 high schools were selected, including 8 classes from each grade. All students from the selected classes were invited to participate in the study.

The study protocol and all procedure conducted in this study were approved by the Ethical Committee for Biomedical Research at the University of Medicine and Pharmacy at Ho Chi Minh City, Vietnam (approval number: 97/ĐHYD-HĐĐĐ). Each selected class, including students and their parents, was informed about the study. Participation was voluntary and based on informed consent obtained from both the students and their parents or guardians. Among 1648 students invited, 21 refused to participate and 129 students did not have consent from their parents or guardians, resulting in 1498 students participating in this study. Among these, 6 students did not complete the questionnaire and were excluded from the analysis. The participation rate was $90.5 \%$ with 1492 students in the analysis. All students completed a selfreported questionnaire which included information about their characteristics, internet use behaviors, living and studying environments, cyber-victimization and depression.

\section{Measurements}

Students' characteristics measured in this study included sex, grade and grade point average in the last semester. Based on educational grading system in Vietnam, grade point average was categorized into low $(<7 / 10)$, average/good $(\geq 7 / 10-8 / 10)$ and very good/excellent $(\geq 8 / 10)$. Questions about internet use behaviors included using internet every day (yes/no) and time spent on using internet ( $<2$ hours/day, $2-4$ hours/day and $>4$ hours/day). Internet addiction was measured using the Internet Addiction Test (IAT). The IAT has 20 items about the level of internet use using a Likert-type rating scale from 1 (never) to 5 (always) ${ }^{16,17}$. The total score ranges from 20 to 100 and was categorized into three levels, including no internet addiction (IAT score $<50$ ), mild/moderate internet addiction (IAT score of 50 - 79) and severe internet addiction (IAT score of 80 or more) ${ }^{18}$. The IAT demonstrates good psychometric properties in previous studies ${ }^{19,20}$ and has been used in Vietnamese adolescents ${ }^{21,22}$. 
Family environment was measured through Parental Bonding Instrument (PBI) ${ }^{23}$. The

125

126

127

128

129

130

131

132

133

134

135

136

137

138

139

140

141

142

143

144

145

146

147

148

149

150

151

152

153

154

scale included 25 questions for both father and mother to measure their care and control. A higher total score indicates higher level of care and control from parents. The PBI has been validated and used in a previous study in Vietnam ${ }^{22}$. In this study, cutoffs from previous studies were used to dichotomize the scores including 24 for father control, 27 for mother control, 12.5 for father care and 13.5 for mother care. Information about the neighborhood environment included economic classification of living location (poor, average, rich), often experience fight, quarrel in the neighborhood (yes/no), often experience crime in the neighborhood (yes/no) and often witness violence among peers in the neighborhood (yes/no). School environment was evaluated using the School Connectedness Scale, which includes 5 Likert-type questions ${ }^{24}$. The total score ranges from 5 to 25 , a higher score indicates a high level of school connectedness the students experienced. The scale has good psychometric properties in previous studies in Vietnamese adolescents ${ }^{25,26}$.

The main variables were cyber victimization and symptoms of depression (SOD). Cyber victimization was measured through the 16-item Cyber Bullying Scale (CBS) ${ }^{27}$. The CBS measures the levels and types of cyber victimization through a 5-point scale from 0 (never) to 4 (always). The experience of cyber victimization was identified when the students reported any level and type of cyber victimization in the past few months. The scale has a high level of internal consistency, construct and concurrent validity ${ }^{27}$. SOD was measured using the Center for Epidemiologic Studies - Depression scale (CES-D) ${ }^{28}$. The CES-D includes 20 items asking about depressive symptoms in the past 7 days through a 4-point scale from 0 (never) to 3 (most of the times). The total score ranges from 0 to 60 and a higher score indicates a higher level of SOD. High levels of reliability and validity of the CES-D in comparison to various standards of depression diagnosis such as Mini-International Neuropsychiatric Interview (MINI), Composite International Diagnostic Interview (CIDI), and Structured Clinical Interview for DSM Disorder (SCID) were reported in previous studies ${ }^{28,29}$. Based on practice from previous studies among adolescents ${ }^{30}$, a cutoff score of 16 was used to classify students with SOD.

\section{Data analysis}

To take the advantage of sampling approach employed, the survey data analysis technique was used to account for the cluster effect and sampling weight. In this study, sampling weight was the inverse of the probability of students being recruited from the selected school. 
155 The sampling weight was used for further analyses including estimation through 95\% confidence 156 interval, statistical tests and logistic regression. Chi-squared tests were used to compare students' 157 characteristics, living, studying environment and cyber victimization between students with SOD 158 and students without SOD. To correct for the survey design, Chi-squared statistics were 159 converted into F statistics. Variables with a $\mathrm{p}$ value of $<0.1$ were included in further analysis 160 using univariate and multivariate logistic regression. Therefore, the association between cyber 161 victimization and SOD was adjusted for other variables. The precision level was set at 5\%.

162 Statistical software Stata version 16 was used for all data analyses.

\section{Results}

164

165

166

167

168

169

170

171

172

173

174

175

176

177

178

179

180

181

182

183

184

185

Among 1492 students in the survey-based analysis, most were females from high schools with an average/good grade point average in the last semester (Table 1). Almost all (92.4\%, 95\% CI $90.3 \%$ - 94.1\%) students reported using the internet every day and nearly $40 \%$ used internet for more than four hours per day. Almost $60 \%$ of students had certain levels of internet addiction, including $57.9 \%$ mild/moderate $(95 \%$ CI 54.2\% - 61.5\%) and $2.5 \%$ severe (95\% CI $1.5 \%-3.9 \%)$. Nearly half of students $(47.8 \%, 95 \%$ CI $43.5 \%-52.1 \%)$ reported SOD. Higher prevalence of SOD was found among female, high school students and those who spent more time on using internet and those who were classified as having internet addiction.

Table 2 presents students' living and studying environment, stratified by SOD. While about $40 \%$ of students reported caring from both father and mother, almost two-thirds disclosed control from them. Approximately $60 \%$ of students experienced fight, quarrel or crime in the neighborhood and one-third witnessed violence among peers in the neighborhood. Students had a moderate level of school connectedness. Cyber-victimization was identified in $36.5 \%$ of students (95\% CI 32.9\% - 40.4\%) and almost 25\% experienced multiple types of cyber-victimization.

Students who received care from parents had a lower level of SOD. In contrast, those who reported control from parents experienced a high level of SOD. A higher level of SOD was also found among students experienced fight, quarrel, crime or witnessed violence among peers in the neighborhood. Students who had a lower level of school connectedness or experienced cybervictimization were more likely to have SOD.

Subgroup analysis was performed for Table 1 and 2 in males and females. Females who had a low grade point average, lived in a higher economical classification location and often experienced fight, quarrel or crime in the neighborhood were more likely to have SOD (Table 
186 1A, 2A). However, this pattern was not found in males. The associations between SOD and other

187 factors were not different in males and females. The association between cyber-victimization and 188 SOD remained statistically significant in both subgroups.

189 Significant variables in Tables 1 and 2 were analyzed in more details in Table 3 . The 190 association between cyber victimization and SOD was statistically significant in both univariate 191 and multivariate analysis. The positive association between cyber victimization and SOD was 192 confirmed after adjusting for other variables. Students who experienced cyber victimization had 1931.81 times (95\% CI $1.42-2.30)$ higher in odds of having symptoms of depression. In addition, a 194 higher likelihood of having SOD was also found among female students who had internet 195 addiction, control from the mother. However, lower odds of having SOD was identified among 196 students with caring from both mother and father and those with a high level of school 197 connectedness.

\section{Discussion}

From a large pool of Vietnamese adolescents in this study, we found a very high prevalence of cyber victimization. Importantly, one-fourth of students experienced multiple types of cyber victimization. Despite using the same measuring scale (i.e., CBS), our figure is lower when compared with results obtained from the USA such as $58,7 \%$ in the study by Stewart, Drescher and Maack ${ }^{27}$ and 67,6\% in the study by Johnson ${ }^{31}$ in studies. Studies in other countries also reported higher figures of cyber victimization prevalence such as Romania $(37.3 \%)^{32}$ and China (44.5\%) ${ }^{33}$. Such differences can be attributed to the characteristic dissimilarity between regions regarding internet development and usage patterns ${ }^{32}$. Particularly, in our study, most cyberbullied students experienced rude comments (such as name-calling or being made fun of) through texting or online platforms. Meanwhile, in a study by Autry in 2016 on 543 US college students, the most common behavior was getting involved in online fights ${ }^{34}$. Moreover, cyberbullying has still been a novel issue in developing countries like Vietnam for students, parents and even educators. However, the prevalence of cyber victimization in our study was relatively higher than previous reports in other regions of Vietnam, for example in Hue $(9.0 \%)^{35}$ and in northern provinces $(24.0 \%)^{36}$.

Our study also unveiled an exceptionally high prevalence of depression among Vietnamese students, compared to other recent domestic studies. For example, depression rates reported in two former studies in Vietnam by Nguyen, Dedding and Pham ${ }^{12}$ and Tran, Le and 
217 Nguyen ${ }^{13}$ were $41.1 \%$ and $37.1 \%$, respectively. Regarding similar studies in the world on

218 adolescents using the same measurement questionnaire, our study found an even higher

219 prevalence. Somrongthong, Wongchalee and Laosee ${ }^{37}$ reported a depression rate in Thailand of

$22034.9 \%$ while Li, Lau and Mo ${ }^{38}$ found that about $23.5 \%$ of adolescents in China had symptoms of

221 depression. All of these findings reveal that depression should be one of the priorities when

222 planning public healthcare interventions for adolescents in all contexts across countries. To

223 optimize the results of healthcare interventions, especially in under-resourced countries, one

224 possible solution is to delineate the high-risk group of depression by identifying potential risk

225 factors. Gender differences should also be considered in such interventions since females might

226 be more vulnerable to SOD than males in some situations.

227 One of the unexplained issues in Vietnam is whether an association between

228 cyberbullying and depression exists. After adjusting for other variables including important

229 factors such as internet addiction and parental bonding, results from the final model in our study

230 indicated that students who experienced cyber victimization had nearly two times higher the

231 odds of having depression. This relationship has been confirmed by a large body of literature

232 worldwide, irrespective of measuring scales of cyberbullying and depression; either evaluating

233 by univariate or multivariate analysis; conducting in different countries with different cultures

234 and timepoints. However, the level of association varies between regions, ranging from $\mathrm{OR}=$

2351.44 in the $\mathrm{UK}^{39}$ to $\mathrm{OR}=2.70$ in the US ${ }^{40}$. In Asia, for example, a study in Taiwan found a 2.54

236 times higher in odds of having depression among those experienced cyber victimization ${ }^{41}$. In

237 addition to the explanation through factors mentioned above, it might also be due to the

238 dissimilar perception about cyber-victimization's severity or variance in the age distribution

239 among different populations in previous studies ${ }^{39,42}$. For example, Agatston, Kowalski and

240 Limber ${ }^{43}$ found that teenage boys living in the USA were less likely to consider cyberbullying as

241 a serious problem. As a result, the association between cyberbullying and depression might not

242 be obvious. Moreover, it is encouraging to understand from our study that several factors such as

243 school connectedness and parental bonding can protect the students against symptoms of

244 depression although the mechanism and role of such factors warrant further investigation.

245 Findings from our study provide some major implications. Cyberbullying is an up-to-date

246 issue overtime intrinsically and should be paid more attention, especially in developing countries

247 where the internet era is thriving but the risks of interacting on cyber-space may not be fully 
248 perceived and understood. Cyberbullying has become more common, yet it received inadequate

249 attention. What matters are that despite not being fully understood, cyberbullying already

250 imposed harm on adolescent health and well-being in many ways, particularly mental health as

251 found in this study and previous studies. Cyberbullying behaviors are being transferred into more

252 sophisticated forms with relation to the development of technology such as the Internet, mobile

253 phone and social networks and many others ${ }^{44}$. Therefore, detailed description of cyberbullying

254 forms may provide a scientific reference for planning appropriate and effective intervention

255 strategies. Additionally, although the effectiveness of legal regulations to control cyberbullying

256 in other countries is unclear ${ }^{45}$, many countries, including Vietnam, lack clear regulations on this

257 issue. Overall, it is suggested that developing relevant policies and regulations are necessary to

258 minimize possible risks in cyber-space. The present of such legislation and the use of reporting

259 system can be beneficial so that cybervictims or their peers can report such cyberbullying cases.

260 Importantly, the Covid-19 pandemic with unavoidable social distancing and lockdown in

261 Vietnam and other countries provides hotbed for cyberbullying and depression among students

262 due to distance learning ${ }^{46}$. This warrants urgent actions to protect this vulnerable population.

263 Several limitations should be noted in this study. Due to the nature of the cross-sectional

264 study where the causal relationship cannot be confirmed. This is also a common limitation of the

265 cross-sectional study design and thus additional follow-up studies should be conducted to

266 determine the causal relationship between cyberbullying and depression. Moreover, this study

267 was conducted in a large city in Vietnam, which is unrepresentative of the whole countries. It is

268 likely that adolescents in other geographic areas, for example rural areas, may have different

269 levels of using internet, different level of depression, and thus the impact of cyberbullying on

270 depression may be different. Therefore, more studies are needed in other provinces and regions

271 in Vietnam. Additionally, more females participated in our study than males and thus might lead

272 to potential biases. Although gender differences in particiation in mental health studies have been

273 commonly reported in Vietnam ${ }^{15,47,48}$, the reasons for this phenomenon and the magnitude of its

274 effect on mental health and related factors warrant further investigations.

275 Conclusions

276 Cyber victimization and depression are both common in Vietnamese adolescents. Those

277 who experienced cyber bullying have a higher likelihood of having symptoms of depression.

278 There is an urgent need for interventions and policies targeting this emerging type of bullying in 
279 Vietnam and similar settings due to its potential harmful effects on adolescents' health. More

280

281

282

283

284

285

286

287

288

289

290

291

292

293

294

295

296

297

298

299

300

301

302

303

304

305

306

307

308

309

310

311

312

313

314

315

316

317

318

319

320

advance studies exploring the role of different types of cyberbullying and other mediators,

moderators are also needed to better understand this association in different contexts.

\section{Acknowledgments}

The authors would like to thank all students participating in this study. We also thank staff at participated schools for their support during data collection.

\section{References}

1. Gladden RM, Vivolo-Kantor AM, Hamburger ME, Lumpkin CD. Bullying surveillance among youths: Uniform definitions for public health and recommended data elements. 2014:pp.1-116.

2. WeAreSocial. Digital in 2020. https://wearesocial.com/digital-2020 (accessed 20 May 2020)

3. Stats IW. Internet Usage in Asia. Accessed accessed on 01/03/2021, https://www.internetworldstats.com/top20.htm (accessed 01 March 2021)

4. Stats IW. Internet Usage in Asia. https://www.internetworldstats.com/stats3.htm (accessed 01 March 2021)

5. Kowalski RM, Giumetti GW, Schroeder AN, Lattanner MR. Bullying in the digital age: A critical review and meta-analysis of cyberbullying research among youth. Psychological bulletin. 2014;140(4):pp. 1-66. doi:10.1037/a0035618

6. Ruiz RMNM. Curbing Cyberbullying among Students: A Comparative Analysis of Existing Laws among Selected Asean Countries. PEOPLE: International Journal of Social Sciences. 2019;4(3):pp.1285-1305. doi:10.20319/pijss.2019.43.12851305

7. Turner MG, Exum ML, Brame R, Holt TJ. Bullying victimization and adolescent mental health: General and typological effects across sex. Journal of Criminal Justice. 2013;41(1):pp. 53-59. doi:10.1016/j.jcrimjus.2012.12.005

8. Le HTH, Nguyen HT, Campbell MA, Gatton ML. Longitudinal associations between bullying and mental health among adolescents in Vietnam. International journal of public health. 2017;62(1):pp. 51-61. doi:10.1007/s00038-016-0915-8

9. Bottino SMB, Bottino C, Regina CG. Cyberbullying and adolescent mental health: systematic review. Cadernos de saude publica. 2015;31:pp. 463-475. doi:10.1590/0102$311 \times 00036114$

10. Landstedt E, Persson S. Bullying, cyberbullying, and mental health in young people. Scandinavian journal of public health. 2014;42(4):pp. 393-399. doi:10.1177/1403494814525004 11. Schneider SK, O'donnell L, Stueve A, Coulter RWS. Cyberbullying, school bullying, and psychological distress: A regional census of high school students. American journal of public health. 2012;102(1):pp. 171-177. doi:10.2105/AJPH.2011.300308

12. Nguyen DT, Dedding C, Pham TT. Depression, anxiety, and suicidal ideation among Vietnamese secondary school students and proposed solutions: a cross-sectional study. BMC public health. 2013;13(1):pp. 1-10. doi:10.1186/1471-2458-13-1195

13. Tran QA, Le VTH, Nguyen THD. Depressive symptoms and suicidal ideation among Vietnamese students aged 13-17: Results from a cross-sectional study throughout four geographical regions of Vietnam. Health psychology open. 2020;7(2):pp.1-7.

Peer) reviewing PDF | (2021:08:65142:1:0:NEW 4 Jan 2022) 
321 14. People's Committee of Ho Chi Minh City. Introduction of Ho Chi Minh City.

322 https://vpub.hochiminhcity.gov.vn/portal/KenhTin/Gioi-thieu-ve-thanh-pho.aspx (accessed 01

323 March 2021)

324 15. Thai TT, Vu NLLT, Bui HHT. Mental health literacy and help-seeking preferences in

325 high school students in ho Chi Minh City, Vietnam. School Mental Health. 2020:pp. 1-10.

326 doi:10.1007/s12310-019-09358-6

327 16. Chang MK, Law SPM. Factor structure for Young's Internet Addiction Test: A

328 confirmatory study. Computers in human behavior. 2008;24(6):pp. 2597-2619.

329 doi:10.1016/j.jadohealth.2016.06.006

330 17. Ni X, Yan H, Chen S, Liu Z. Factors influencing internet addiction in a sample of

331 freshmen university students in China. Cyberpsychology \& behavior. 2009;12(3):pp. 327-330.

332 doi:10.1089/cpb.2008.0321

333 18. Fatehi F, Monajemi A, Sadeghi A. Quality of life in medical students with internet

334 addiction. Acta Medica Iranica. 2016:pp. 662-666. doi:10.4103/jfmpc.jfmpc_986_19

335 19. Milani L, Osualdella D, Blasio PD. Quality of interpersonal relationships and problematic

336 Internet use in adolescence. CyberPsychology \& Behavior. 2009;12(6):pp. 681-684.

337 doi: $10.1089 / \mathrm{cpb} .2009 .0071$

338 20. Boysan M, Kuss DJ, Barut Y. Psychometric properties of the Turkish version of the

339 Internet Addiction Test (IAT). Addictive behaviors. 2017;64:pp. 247-252.

340 doi:10.1016/j.addbeh.2015.09.002

341 21. Dang HM, Nguyen TP. Correlation Between the Level of Internet Usage and Mental

342 Health Problems at Secondary School Students in Hanoi. VNU Journal of Science: Education

343 Research. 2013;29(2):pp.34-42.

344 22. Thai TT, Nguyen TV, Tran TAT. The association between internet addiction and

345 depression in Nguyen Cong Tru secondary school students in Bien Hoa city, Dong Nai. Ho Chi

346 Minh City Journal of Medicine. 2018;22(1): pp. 339- 346.

347 23. Parker G, Tupling H, Brown LB. A parental bonding instrument. British Journal of

348 Medical Psychology. 1979;52(1):1-10. doi:10.1111/j.2044-8341.1979.tb02487.x

349 24. Furlong MJ, O'brennan LM, You S. Psychometric properties of the Add Health School

350 Connectedness Scale for 18 sociocultural groups. Psychology in the Schools. 2011;48(10):pp.

351 986-997. doi:10.1002/pits.20609

352 25. Thai TT. Educational stress and mental health among secondary and high school

353 students in Ho Chi Minh city, Vietnam. Queensland University of Technology; 2010.

354 26. Thai TT, Tran PD. Associated factors of suicidal ideation among high school students in

355 Tay Ninh. Ho Chi Minh City Journal of Medicine. 2016;20(1):pp. 163-168.

356 27. Stewart RW, Drescher CF, Maack DJ. The development and psychometric investigation

357 of the Cyberbullying Scale. Journal of interpersonal violence. 2014;29(12):pp. 2218-2238.

358 doi:10.1177/0886260513517552

359 28. Radloff LS. The use of the Center for Epidemiologic Studies Depression Scale in

360 adolescents and young adults. Journal of youth and adolescence. Apr 1991;20(2):149-66.

361 doi:10.1007/BF01537606

362 29. Vilagut G, Forero CG, Barbaglia G, Alonso J. Screening for Depression in the General

363 Population with the Center for Epidemiologic Studies Depression (CES-D): A Systematic

364 Review with Meta-Analysis. PLoS One. 2016;11(5):e0155431-e0155431.

365 doi:10.1371/journal.pone.0155431 
366

367

368

369

370

371

372

373

374

375

376

377

378

379

380

381

382

383

384

385

386

387

388

389

390

391

392

393

394

395

396

397

398

399

400

401

402

403

404

405

406

407

408

409

410

411

30. Thai TT, Kim XL, Nguyen ND, Dixon J, Sun J, Dunne MP. Validation of the Educational Stress Scale for Adolescents (ESSA) in Vietnam. Asia Pac J Public Health. Mar 2015;27(2):NP2112-21. doi:10.1177/1010539512440818

31. Johnson KL. Oh, what a tangled web we weave: Cyberbullying, anxiety, depression, and loneliness. The University of Mississippi; 2016.

32. Athanasiou K, Melegkovits E, Andrie EK. Cross-national aspects of cyberbullying victimization among 14-17-year-old adolescents across seven European countries. BMC public health. 2018;18(1):pp.1-15. doi:10.1186/s12889-018-5682-4

33. Rao J, Wang H, Pang M. Cyberbullying perpetration and victimisation among junior and senior high school students in Guangzhou, China. Injury prevention. 2019;25(1):pp. 13-19. doi:10.1136/injuryprev-2016-042210

34. Autry AL. The Role Of Loneliness And Resilience In Psychosocial Health For Victims Of Cyberbullying In A College Population. Electronic Theses and Dissertations. 2016:pp.1-60. doi:https://egrove.olemiss.edu/etd/831

35. Nguyen HTL, Nakamura K, Seino K. Relationships among cyberbullying, parental attitudes, self-harm and suicidal behavior among adolescents: results from a school-based survey in Vietnam. BMC public health. 2020;20(1):pp. 1-9. doi:10.1186/s12889-020-08500-3

36. Le QT. A study of the core relationship between cyber-bullying and coping of highschool pupils in Vietnam. Int J Innov Creat Chang. 2020;11(3):pp. 483-500.

37. Somrongthong R, Wongchalee $\mathrm{S}$, Laosee O. Depression among adolescents: a study in a Bangkok slum community. Scandinavian journal of caring sciences. 2013;27(2):pp. 327-334. doi:10.1111/j.1471-6712.2012.01037.x

38. Li JB, Lau JTF, Mo PKH. Insomnia partially mediated the association between problematic Internet use and depression among secondary school students in China. Journal of behavioral addictions. 2017;6(4):pp. 554-563. doi:10.1556/2006.6.2017.085

39. Fahy AE, Stansfeld SA, Smuk M. Longitudinal associations between cyberbullying involvement and adolescent mental health. Journal of Adolescent Health. 2016;59(5):pp. 502509. doi:10.1016/j.jadohealth.2016.06.006

40. Alhajji M, Bass S, Dai T. Cyberbullying, mental health, and violence in adolescents and associations with sex and race: data from the 2015 Youth Risk Behavior Survey. Global pediatric health. 2019;6:pp.1-6. doi:10.1177/2333794X19868887

41. Chang FC, Chiu CH, Miao NF. The relationship between parental mediation and Internet addiction among adolescents, and the association with cyberbullying and depression. Comprehensive psychiatry. 2015;57:pp. 21-28. doi:10.1016/j.comppsych.2014.11.013 42. Nixon CL. Current perspectives: the impact of cyberbullying on adolescent health. Adolescent health, medicine and therapeutics. 2014;5:pp. 143-158. doi:10.2147/AHMT.S36456 43. Agatston PW, Kowalski R, Limber S. Students' perspectives on cyber bullying. Journal of Adolescent Health. 2007;41(6):pp. 59-60. doi:10.1016/j.jadohealth.2007.09.003

44. Khan F, Limbana T, Zahid T, Eskander N, Jahan N. Traits, Trends, and Trajectory of Tween and Teen Cyberbullies. Cureus. 2020;12(8):e9738-e9738. doi:10.7759/cureus.9738 45. Foody M, Samara M, El Asam A, Morsi H, Khattab A. A review of cyberbullying legislation in Qatar: Considerations for policy makers and educators. International Journal of Law and Psychiatry. 2017/01/01/ 2017;50:45-51. doi:https://doi.org/10.1016/j.ijlp.2016.10.013 46. Yang F. Coping strategies, cyberbullying behaviors, and depression among Chinese netizens during the COVID-19 pandemic: a web-based nationwide survey. Journal of affective disorders. 2021;281:138-144. doi:10.1016/j.jad.2020.12.023 
412 47. Thai TT, Cao PLT, Kim LX, Tran DP, Bui MB, Bui HHT. The effect of adverse 413 childhood experiences on depression, psychological distress and suicidal thought in Vietnamese 414 adolescents: Findings from multiple cross-sectional studies. Asian Journal of Psychiatry.

415 2020/10/01/2020;53:102134. doi:10.1016/j.ajp.2020.102134

416 48. Thai TT, Jones MK, Nguyen TP, et al. The Prevalence, Correlates and Functions of Non417 Suicidal Self-Injury in Vietnamese Adolescents. Psychology Research and Behavior

418 Management. 2021;2021(14):1915-1927. doi:10.2147/PRBM.S339168

419

420 


\section{Table $\mathbf{1}$ (on next page)}

Table 1: Characteristics and Internet Use Behaviors Among Vietnamese Adolescents, Stratified by Symptoms of Depression 
1 Table 1: Characteristics and Internet Use Behaviors Among Vietnamese Adolescents, Stratified 2 by Symptoms of Depression.

\begin{tabular}{|c|c|c|c|}
\hline \multirow{3}{*}{ Characteristics } & \multirow{2}{*}{$\begin{array}{c}\text { Total } \\
\mathrm{n}=1492\end{array}$} & \multicolumn{2}{|c|}{ Symptoms of depression } \\
\hline & & $\begin{array}{c}\text { Yes } n=673 \\
47.8 \%(43.5-52.1)\end{array}$ & $\begin{array}{c}\text { No } n=819 \\
52.2 \%(47.9-56.5)\end{array}$ \\
\hline & $n($ Weighted $\%, 95 \%$ CI) & $n($ Weighted $\%, 95 \% C I)$ & $n($ Weighted $\%, 95 \%$ CI) \\
\hline \multicolumn{4}{|c|}{ Background information } \\
\hline Sex & & \multicolumn{2}{|c|}{$\chi^{2}(d f=1)=13.7 ; F(1,39)=16.2 ; p<0.001$} \\
\hline Female & $815(55.3,50.4-60.0)$ & $405(60.2,55.0-65.3)$ & $410(50.7,45.3-56.1)$ \\
\hline Male & $677(44.7,40.0-49.6)$ & $268(39.8,34.7-45.0)$ & $409(49.3,43.9-54.7)$ \\
\hline Grade & & \multicolumn{2}{|c|}{$\chi^{2}(d f=1)=35.9 ; F(1,39)=37.2 ; p<0.001$} \\
\hline High school & $892(71.8,56.2-83.5)$ & $460(79.1,65.1-88.5)$ & $432(65.2,48.4-78.8)$ \\
\hline Secondary school & $600(28.2,16.5-43.8)$ & $213(20.9,11.5-34.9)$ & $387(34.8,21.2-51.6)$ \\
\hline Grade point average in th & last semester & \multicolumn{2}{|c|}{$\chi^{2}(d f=2)=2.9 ; F(2,77.1)=1.0 ; p=0.363$} \\
\hline $\begin{array}{l}\text { Very good/Excellent } \\
(\geq 8 / 10)\end{array}$ & $517(33.8,26.9-41.5)$ & $218(32.1,24.9-40.3)$ & $299(35.3,27.7-43.7)$ \\
\hline $\begin{array}{l}\text { Average/Good ( } \geq 7 / 10 \text { - } \\
8 / 10)\end{array}$ & $683(48.1,42.6-53.8)$ & $311(48.3,42.3-54.3)$ & $372(48.0,41.5-54.6)$ \\
\hline Low $(<7 / 10)$ & $292(18.1,13.8-23.4)$ & $144(19.6,14.8-25.5)$ & $148(16.7,11.9-22.8)$ \\
\hline \multicolumn{4}{|c|}{ Internet use behaviors } \\
\hline Using internet every day & & \multicolumn{2}{|c|}{$\chi^{2}(d f=1)=3.2 ; F(1,39)=2.1 ; p=0.151$} \\
\hline Yes & $1366(92.4,90.3-94.1)$ & $609(91.1,88.0-93.5)$ & $757(93.6,90.8-95.6)$ \\
\hline No & $126(7.6,5.9-9.7)$ & $64(8.9,6.5-12.0)$ & $62(6.4,4.4-9.2)$ \\
\hline \multicolumn{2}{|c|}{ Time spent on using internet (hours/day) } & \multicolumn{2}{|c|}{$\chi^{2}(d f=2)=10.5 ; F(1.9,74.7)=5.3 ; p=0.008$} \\
\hline$<2$ & $247(15.5,13.2-18.1)$ & $101(14.2,11.2-17.9)$ & $146(16.6,13.8-19.8)$ \\
\hline $2-4$ & $684(46.6,43.6-49.7)$ & $288(43.6,39.1-48.2)$ & $396(49.4,46.1-52.8)$ \\
\hline$>4$ & $561(37.9,34.0-42.0)$ & $284(42.2,37.2-47.3)$ & $277(34.0,30.1-38.1)$ \\
\hline Internet addiction & & \multicolumn{2}{|c|}{$\chi^{2}(d f=2)=132.9 ; F(1.9,74.2)=56.8 ; p<0.001$} \\
\hline No & $611(39.6,35.7-43.7)$ & $174(25.2,20.7-30.2)$ & $437(52.9,49.7-56.1)$ \\
\hline Mild/moderate & $848(57.9,54.2-61.5)$ & $470(70.3,65.5-74.6)$ & $378(46.6,43.4-49.8)$ \\
\hline Severe & $33(2.5,1.5-3.9)$ & $29(4.6,2.9-7.2)$ & $4(0.5,0.2-1.6)$ \\
\hline
\end{tabular}




\section{Table 2 (on next page)}

Table 2: Living and Studying Environment and Cyber Victimization Among Vietnamese Adolescents, Stratified by Symptoms of Depression 
1 Table 2: Living and Studying Environment and Cyber Victimization Among Vietnamese

2 Adolescents, Stratified by Symptoms of Depression.

\begin{tabular}{cccc} 
& Total & \multicolumn{2}{c}{ Symptoms of depression } \\
\cline { 2 - 4 } Characteristics & $\mathrm{n}=1492$ & Yes $\mathrm{n}=673$, & No $\mathrm{n}=819$, \\
& $n($ Weighted $\%, 95 \%$ & $47.8 \%(43.5-52.1)$ & $52.2 \%(47.9-56.5)$ \\
$C I)$ & $n($ Weighted $\%, 95 \%$ CI $)$ & $n($ Weighted $\%, 95 \%$ CI)
\end{tabular}

\section{Family environment}

\section{Living with whom}

With parents

With either mother or father

With others

\section{Parental bonding}

$$
\begin{gathered}
1275(83.6,79.8-86.9) \\
174(13.2,10.4-16.5)
\end{gathered}
$$$$
43(3.2,2.4-4.2)
$$$$
543(78.4,73.0-83.0)
$$$$
102(16.9,12.7-22.1)
$$$$
28(4.7,3.5-6.2)
$$

$$
\chi^{2}(d f=2)=28.1 ; F(1.7,66.1)=12.8 ; p<0.001
$$

$732(88.4,84.9-91.1)$

$72(9.7,7.4-12.7)$

$$
15(1.9,1.2-3.0)
$$

Caring from father

Control from father

$$
658(45.6,41.1-50.2)
$$

$$
\chi^{2}(d f=1)=140.5 ; F(1,39)=128.9 ; p<0.001
$$

$$
179(28.5,24.8-32.5) \quad 479(60.6,55.1-65.7)
$$

$$
\chi^{2}(d f=1)=28.7 ; F(1,39)=18.4 ; p<0.001
$$

$$
847(62.7,59.2-66.0) \quad 424(70.2,64.5-75.3) \quad 423(56.1,52.2-59.9)
$$

Caring from mother

$$
\chi^{2}(d f=1)=140.9 ; F(1,39)=88.0 ; p<0.001
$$

$$
574(39.2,35.2-43.3) \quad 137(22.4,17.9-27.6) \quad 437(53.5,49.1-57.9)
$$

Control from mother

$$
863(62.7,59.3-66.0)
$$

$$
\chi^{2}(d f=1)=71.0 ; F(1,39)=64.1 ; p<0.001
$$

$$
448(74.5,69.7-78.8) \quad 415(52.7,49.1-56.2)
$$

\section{Neighborhood environment}

\section{Economical classification of living location}

Poor

Average

Rich
$46(3.2,2.4-4.4)$

$1362(90.8,88.7-92.6)$

$84(5.9,4.7-7.5)$
Often experience fight, quarrel in the neighborhood

$$
\begin{aligned}
& \text { Yes } \\
& \text { No }
\end{aligned}
$$
$\chi^{2}(d f=2)=4.5 ; F(2.0,76.5)=1.9 ; p=0.152$

$$
\begin{array}{cc}
26(4.1,2.5-6.5) & 20(2.5,1.7-3.7) \\
602(89.3,86.0-91.8) & 760(92.3,89.8-94.2) \\
45(6.7,5.0-8.9) & 39(5.2,3.7-7.4)
\end{array}
$$

$$
\chi^{2}(d f=1)=8.2 ; F(1,39)=4.5 ; p=0.041
$$

$$
\begin{array}{rc}
455(67.5,62.7-71.9) & 493(60.3,55.9-64.6) \\
218(32.5,28.1-37.3) & 326(39.7,35.4-44.1) \\
\chi^{2}(d f=1)=12.3 ; F(1,39)=5.6 ; p=0.023 \\
424(63.5,57.1-69.3) & 431(54.5,50.0-59.0) \\
249(36.5,30.7-42.9) & 388(45.5,41.0-50.0)
\end{array}
$$

$$
\chi^{2}(d f=1)=26.3 ; F(1,39)=23.6 ; p<0.001
$$

neighborhood

Yes

No

$$
477(33.8,30.7-37.1)
$$$$
1015(66.2,62.9-69.3)
$$

$262(40.4,36.0$ - 45.0)

$215(27.8,24.7-31.2)$

$411(59.6,55.0$ - 64.0) 


\section{School environment}

\begin{tabular}{|c|c|c|c|}
\hline $\begin{array}{l}\text { School connectedness } \\
\text { score }(\text { Mean \& } 95 \% \text { CI) }\end{array}$ & $18.9(18.5-19.3)$ & $17.9(17.4-18.3)$ & $\begin{array}{l}F(1,39)=53.3 ; p<0.001 \\
19.8(19.4-20.2)\end{array}$ \\
\hline \multicolumn{4}{|c|}{ Cyber victimization } \\
\hline \multicolumn{2}{|l|}{ Cyber victimization } & \multicolumn{2}{|c|}{$\chi^{2}(d f=1)=84.3 ; F(1,39)=80.7 ; p<0.001$} \\
\hline Yes & $528(36.5,32.9-40.4)$ & $321(48.5,43.3-53.7)$ & $207(25.6,22.2-29.3)$ \\
\hline No & $964(63.5,59.6-67.1)$ & $352(51.5,46.3-56.7)$ & $612(74.4,70.7-77.8)$ \\
\hline \multicolumn{2}{|c|}{ Number of cyber-victimized forms experienced } & \multicolumn{2}{|c|}{$\chi^{2}(d f=4)=91.1 ; F(3.6,141.4)=21.7 ; p<0.001$} \\
\hline 0 & $964(63.5,59.6-67.1)$ & $352(51.5,46.3-56.7)$ & $612(74.4,70.7-77.8)$ \\
\hline 1 & $201(12.8,11.2-14.6)$ & $114(15.3,12.6-18.5)$ & $87(10.5,8.7-12.7)$ \\
\hline 2 & $136(9.5,8.0-11.3)$ & $78(12.4,9.8-15.6)$ & $58(6.9,5.2-9.0)$ \\
\hline 3 & $99(7.0,5.7-8.4)$ & $68(10.3,8.3-12.8)$ & $31(3.9,2.8-5.5)$ \\
\hline $4+$ & $92(7.2,5.4-9.7)$ & $61(10.5,7.9-13.8)$ & $31(4.3,2.7-6.7)$ \\
\hline
\end{tabular}




\section{Table 3 (on next page)}

Table 3: Factors Associated with Symptoms of Depression Among Vietnamese Adolescents 
1 Table 3: Factors Associated with Symptoms of Depression Among Vietnamese Adolescents $2(\mathrm{~N}=1492)$

\begin{tabular}{|c|c|c|c|c|}
\hline \multirow{3}{*}{ Characteristics } & \multicolumn{4}{|c|}{ Symptoms of depression } \\
\hline & Crude & & Adjusted* & \\
\hline & $\begin{array}{c}\text { Weighted OR } \\
\text { (95\% CI) }\end{array}$ & $\mathbf{p}$ & $\begin{array}{c}\text { Weighted OR } \\
\text { (95\% CI) }\end{array}$ & $\mathbf{p}$ \\
\hline Sex (female) & $1.47(1.21-1.79)$ & $<0.001$ & $1.80(1.32-2.46)$ & $<0.001$ \\
\hline Grade (high school) & $2.03(1.60-2.57)$ & $<0.001$ & $1.20(0.94-1.54)$ & 0.143 \\
\hline
\end{tabular}

Time spent on using internet (hours/day)

\begin{tabular}{lcccc}
$<2$ & 1 & \multicolumn{3}{c}{ Ref } \\
$2-4$ & $1.03(0.73-1.44)$ & 0.875 & $0.72(0.47-1.12)$ & 0.145 \\
$>4$ & $1.44(1.05-1.98)$ & 0.024 & $1.13(0.71-1.80)$ & 0.600
\end{tabular}

\section{Internet addiction}

No

Mild/moderate

Severe
1

$$
\begin{array}{cc}
3.17(2.49-4.04) & <0.001 \\
18.04(5.38-60.48) & <0.001
\end{array}
$$

Ref

$$
2.17(1.67-2.82)<0.001
$$$$
9.98(3.71-26.81)<0.001
$$

\section{Living with whom}

With parents

1

With either mother or father

With others

\section{Parental bonding}

Caring from father

Control from father

Caring from mother

Control from mother

Often experience fight, quarrel in the neighborhood

Often experience crime in neighborhood

Experience violence among peers in the neighborhood

School connectedness score

Cyber victimization

$$
\begin{array}{cc}
1.96(1.32-2.92) & 0.001 \\
2.81(1.67-4.71) & <0.001 \\
& \\
0.26(0.20-0.33) & <0.001 \\
1.84(1.38-2.46) & <0.001 \\
0.25(0.18-0.34) & <0.001 \\
2.63(2.05-3.37) & <0.001
\end{array}
$$$$
1.52(0.57-4.03)
$$$$
0.390
$$$$
1.87(0.48-7.39) \quad 0.358
$$

Ref

$$
\begin{array}{lllc}
0.26(0.20-0.33) & <0.001 & 0.51(0.39-0.67) & <0.001 \\
1.84(1.38-2.46) & <0.001 & 0.81(0.57-1.16) & 0.243 \\
0.25(0.18-0.34) & <0.001 & 0.48(0.36-0.65) & <0.001 \\
2.63(2.05-3.37) & <0.001 & 2.04(1.51-2.77) & <0.001
\end{array}
$$

$$
1.36(1.01-1.83) \quad 0.041
$$$$
1.00(0.67-1.51) \quad 0.988
$$$$
1.45(1.06-1.99) \quad 0.023
$$$$
1.04(0.72-1.50)
$$

$1.76(1.39-2.23) \quad<0.001 \quad 1.01(0.75-1.37) \quad 0.930$

$0.86(0.82-0.89)<0.001 \quad 0.89(0.86-0.93)<0.001$ $2.74(2.18-3.45) \quad<0.001 \quad 1.81(1.42-2.30)<0.001$

* Adjusted for other variables in the table 
